\title{
The President's Message
}

The other day, just out of curiosity 1 picked up and reread the report on the meeting of the Saskatchewwan Natural History Society held six years ago. At that first gathering a scant dozen or so people heard the chairman state that there were a mere 270 paid.-up memberships whose total contribution of $\$ 270$ was somehow to take care of the $\$ 400$ necessary just to print the Blue Jay for one year not to mention a host of incidental expenses that would have to be met if the project was to continue. At that moment the future of our publication looked anything but bright. Yet in the years that followed the Blue Jay didn't skip a single issue. In spite of rising costs of publication and continued improvement in quality, it has wound up financially solvent, in fact a modest reserve has been built up.

In contrast to that early meeting our annual conventions now draw large crowds with representation from points in the province and our membership now numbers over 2,000. Space does not permit naming all rhose dedicated individuals who made this possible but I would like to mention two who were, so to say, in the centre of things. A good deal of credit for guiding the destiny of the Blue Jay through those trying years should go to its editor, Lloyd T. Carmichael. Mr. Carmichael has now retired from that position and has been succeeded by Dr. G. F. Ledingham who during the same period in successive roles of President, Secretary-Treasurer and Business Manager has conscientiously performed a multitude of duties in the interest of the organization and no doubt will show the same devotion to the cause of wildlife conservation in the new capacity.

But an editor by himself cannot assure success of a publication. The Blue Jay is a type of periodical that aims to appeal to every citizen who is interested in the preservation of our wilderness resources and in the main depends for its material on the contributions by its readers. Only if the editor has a large pool of source material from which he can make his selection can he hope to maintain the quality of the Blue Jay. I also want to draw special attention to the Boys' and Girls' section. Children by nature are very inquisitive and often note wildlife phenomena that would pass unobserved by their elders. Let's encourage them to share their experiences with others through the medium of the Blue Jay; and besides there are some excellent prizes for good stories.

While it is true that the circulation of Blue Jay in recent years has shown a very encouraging increase, it is also true that many communities have never heard either of the Saskatchewan Natural History Society or its organ. To those who feel that not much can be done in smaller communities it should be pointed out that the Blue Jay itself got its start in a small community. What has been done in Yorkton can be duplicated elsewhere. Nature is a subject that has universal appeal and conservation is something that everyone talks about; the S.N.H.S. and the Blue Jay give everybody a chance to do something about it. 